\title{
EM DIREÇÃO A UMA COSMOPOLÍTICA DA IMAGEM: \\ NOTAS PARA UMA POSSÍVEL ECOLOGIA DE \\ PRÁTICAS CINEMATOGRÁFICAS'
}

TOWARDS A COSMOPOLITICS OF IMAGE:

NOTES ON A POSSIBLE ECOLOGY OF CINEMATIC PRACTICES

\section{Sebastian Wiedemann FE/Unicamp}

\section{Resumo}

A partir de uma disposição performática, este texto se propõe a ser um gesto de experimentação filosófica e audiovisual, que instaura um plano misto do pensamento entre audiovisualidades e conceitualidades do qual de modo imanente emerge a noção de cosmopolítica da imagem, como emanação de uma ecologia de práticas em ato que se nutre do encontro e devir com potências de pensamento da diferença, da expressividade matérica e de povos extra-modernos como os Yanomami e Yoruba. Em última instância, a tentativa de uma aventura do pensamento como gesto descolonizador da imagem através da proliferação de modos de experiência cinematográficos.

\section{Palavras-chave:}

Gilles Deleuze; Isabelle Stengers; Modos de experiência cinematográficos; Experimentação audiovisual filosófica; Filosofia-performance.

Devir guardião do díspar, do diferencial, experimentar limiaridades e passagens do possível nas gradações de outrem entre mundos. Blocos de audiovisualidades como gestos cosmopolíticos. No encontro e violência com potencialidades imagéticas e sonoras que escapam ao humano, que são mais do que humanas por serem elementares ou extra-modernas, saber que ali encontra-se o germe de um pensamento sem imagem que paradoxalmente se afirma na vertigem imagética/ audiovisual que infindavelmente adia a chegada e cristalização de uma imagem no pensamento.

\section{Abstract}

Starting from a performatic disposition, this text proposes to be a gesture of philosophical and audiovisual experimentation, which introduces a mixed plane of thought between audiovisualities and conceptualities from which in an immanent way emerges the notion of cosmopolitics of image, as an emanation of an ecology of practices in the act that nourishes itself from the encounter and becoming with potencies of thought of the difference, of matter expressiveness and of extramodern peoples like the Yanomami and Yoruba. Ultimately, the attempt of an adventure of thought as a decolonizing gesture of the image through the proliferation of modes of cinematic experience.

Keywords:

Gilles Deleuze; Isabelle Stengers; Cinematic modes of experience; Philosophical audiovisual experimentation; Philosophy-performance.

O plano do sensível se deixando arrastar pelo outro do outro que sacode o pensamento, que o mantem em movimento instaurando por sua vez uma ecologia de práticas cinematográficas que passam pelo filme, mas também pelo papel, pela escrita. Potencialidades imagéticas, sonoras e conceituais se imbricando e compondo um plano misto do pensamento que enriquece esta ecologia singular de práticas ao incorporar não só mais técnicas, mas com elas modos outros de experiência. Isto é, de fazer existir. Podemos dizer então que pensar é sempre pensar por outros 
meios. Mas os meios como superfícies deslizantes e de passagem, não são só materialidades como o filme e o papel, mas também materialidades como as potências cosmogenéticas de outros povos. Esta é a questão problematizante que quero explorar e complicar nesta intervenção/gesto ao passar por quatro filmes, "Abismo" (2012), "Xapirimuu" (2016), "Obatala Film" (2019) e "Cintilações" (2018), que fiz no encontro com diversas potências cosmogenéticas. A saber, as potências moleculares da cor, as potências de pensamento Yanomami, Yoruba e da filosofia da diferença respectivamente.

Gostaria de começar por uma formula que me parece, de modo eficaz, diz das exigências do gesto que aqui quero desdobrar:

Fazer existir e não julgar, estando à altura de outrem.

Nesta formulação sem dúvida ressoa Deleuze (1997; 2015) e é nesse ressoar que quero pensar com ele, mas, sobretudo, com a filosofa das ciências Isabelle Stengers em direção a um empirismo especulativo (SAVRANSKY, 2019). Neste balançar, co-pensar também nos leva ao encontro da antropologia e de suas aproximações aos mundos ameríndios, assim como aos encontros afetivos que tenho tido com o povo Yoruba, em especial com babalawos da cidade de lle-Ife na Nigéria. Um pensar com desde a perspectiva de um cineasta, ou para melhor dizer, de um praticante de modos de experiência cinematográficos. Todo um pensar por multiplicidades e conexões parciais (STRATHERN, 2005) e transversais que dão consistência ao que Stengers chama de ecologia de práticas (STENGERS, 2005).

Assim como Stengers não posso negar que sou herdeiro das luzes e no caso do cinema, também das catedrais. A prática cinematográfica não é nem neutral nem inocente, não esqueçamos que assim como a Internet ela surgiu por motivações militares. A infância do cinema é ínfima, se pensarmos quanto tempo passou para que se impusesse uma clara distinção entre magia, alquimia e química. O cinema é produto da vida moderna, do pensamento moderno, ele já nasceu numa chave maior para usar as palavras de Stengers. Uma chave maior, uma maioridade prematura que confina o potencial de experimentação e criação da prática ao submetê-la às logicas da representação e do mercado. A primazia de um naturalismo, onde ou o mundo se faz imagem, ou nos é dada uma imagem do mundo, quando, ou pelo menos para as práticas que pretendem afirmar a formula/proposição que aqui quero desdobrar, o que deveria emergir é a potência genética de um mundo sem imagem. Isto é um mundo que sempre está por ser feito, um pluriverso, se pensarmos com William James (2003). Mas certamente o dispositivo cinematográfico reproduz aquilo que Alfred North Whitehead chamou de bifurcação da natureza (WHITEHEAD, 2007) e onde para uma natureza, para um mundo unívoco, há um multiculturalismo em vez de um multinaturalismo (VIVEIROS DE CASTRO, 2018). Impõe-se então um sair do cinema pelo meio do próprio cinema. Se faz iminente uma descolonização do cinema, se quisermos que ele pare de julgar, de reproduzir, de representar. Se quisermos que ele se torne meio para uma efetiva aventura do pensamento.

Falamos da emergência de um cinema antes de saber Cinema, de um cinema em chave menor, poroso e aberto a contágios e alianças impensadas, onde se abraça a instabilidade e vulnerabilidade dos devires na ausência de fundamento, de essência ou de formas a priori. Um cinema que se arisca, que experimenta. Um cinema experimental que dá vazão ao cosmos, a conexões pelas diferenças e em consequência se diz cosmopolítico. Um cinema cuja preocupação não é mais a reprodução de um mundo e com esta a reprodução de uma moral. Um cinema que como modo de experiência, puro (JAMES, 2003) e imanente com a vida mesma, só pode ser um cinema do processo (WHITEHEAD, 1978).

Neste cinema do processo proliferam modos de experiência (cinematográficos), cuja tendência se move por duas propensões. Por um lado, a pergunta pelo intervalo, que como veremos mais adiante não está muito distante do gesto de estar à altura de outrem, e, por outro, por como em meio a um processo cosmogenético de proliferação de heterogêneos, as visualidades e sonoridades se apresentam como atratores do movimento e do movente do pensamento. Isto é, a série é e deve ser aberta, incluindo os mais diversos modos de experiência, assim como o contágio entre divergentes meios, superfícies e práticas. No entanto, as visualidades 
e sonoridades são os vetores propulsores do pensamento, abismando-o no intervalo, de onde uma novidade, uma disparidade ou diferencial pode emergir. A qualidade assignificante das visualidades e sonoridades tendem a criar uma maior vertigem no diagrama e, com ela, uma maior potência de queda, que faz com que a imagem seja sempre aquilo que está por vir. Um cinema que se preocupa pelo desabrochar constante e infindável de um mundo pluralista. Em outras palavras, que se preocupa pela variabilidade, transmutabilidade e multirelacionalidade (ORLANDI, 2016) das matrizes perceptivas e cuja nascença eclode dos intervalos. Este cinema metamórfico, certamente, pode independer do filme ou como está acontecendo em ato neste instante, pode devir filme por outros meios, como pode sêlo a escrita e sua prática de conceitualização. $E$, nesse sentido, poderíamos talvez, e desde a perspectiva que estamos defendendo, afirmar que já são modos de experiência cinematográficos, as práticas dos xamãs Yanomami em relação aos xapiripë como uma espécie de cinema somático e encorpado, assim como as práticas de divinação dos babalawos em relação ao corpo literário e divinatório de Ifa como uma espécie de cinema episódico e especulativo?

Antes de testar a eficácia destas especulações sugiro que nos abismemos na vertigem de um primeiro intervalo com o filme "Abismo" (2012), figura 1.

Descolonizar o cinema, levando ao maior grau de singularidade suas potências expressivas. Não há cinema que possa se constituir como uma ecologia de práticas se este se diz, em geral, de modo genérico e querendo reproduzir uma vontade universalizante. Desmontar seus a priori. A potência cinematográfica não pode ser reduzida à figuração, à representação e a sua lógica de causa e efeito. E nem se quer podemos chegar a pressupor que precisa de uma câmera para que aconteça, ou que seja subsidiária de uma vontade de analogia com a realidade e de vícios herdados da literatura e do teatro. O cinema pode acontecer como um cinema-papel, como o que vocês agora estão escutando/lendo, mas também pode acontecer como um gesto tátil de pintar sobre a própria materialidade do filme, como em "Abismo". Este cinema se descoloniza de qualquer vontade transcendente para fazer corpo com e se recusar a abandonar a experiência pura (JAMES, 2003) onde, enquanto a prática emerge, o praticante também o faz. Isto é, o que está em jogo, por exemplo, no caso de fazer corpo com o filme e pintar fotograma por fotograma, é como fazer durar essa ocasião em que mutuamente prática e praticante estão integrados no processo cosmogenético, no processo de nascença de mundos. Processo que pode integrar quantos componentes a ecologia seja capaz de dar consistência e de sustentar no plano da experiência, mas ao mesmo tempo sabendo que nunca atingira uma autossuficiência. Sempre está por se fazer, assim como a imagem sempre está por vir. Quantas variedades cromáticas e moleculares o filme consegue suportar? Quantos mundos diferentes e em estado instável consegue fazer proliferar a prática de cinema feito à mão com a técnica de dripping à maneira de Pollock? Para um cinema do processo, sempre interessara muito mais as qualidades intensivas do que as quantidades extensivas, pois é no plano intensivo que as componentes se vêm obrigadas a estar em seu maior grau de ativação. Isto é, de experimentação, de experienciação e resposibidade.

O mundo, os mundos, o pluriverso está se fazendo e, com ele, nós também. Dobrados na experiência, tudo está em movimento e em chave menor este pensamento cinematográfico em ato, que não para de acontecer, apaga hierarquias e na ausência delas a aventura germina. A ecologia de práticas na sua porosidade e baixa aderência é "uma ferramenta para pensar o que está acontecendo" (STENGERS, 2005), enquanto acontece e onde na vertigem do novo, do intervalo que o convoca; ela, a ferramenta, não se pode deixar fixar num hábito que diga de recognições. A cada vez, a ecologia é outra, a cada vez os acoplamentos são diferentes. Os agenciamentos nunca proliferam do mesmo modo, pois o que estão proliferando é um corpo conectivo e rizomático de afetações entre configurações de mundos divergentes sem algo em comum a priori. Tinta e celuloide não pressupõem uma relação. A cada vez o plano da experiência cinematográfico é re-modulado como zona crítica de alta complexidade e heterogeneidade, sempre com um ponto de apoio local, mas ilocalizável que faz com que não se cristalize ou sedimente como imagem, mas que seja fonte para essa imagem que sempre se diz potência de futuridade, de porvir.

Neste fluxo da experiência não há filme, embora se afirme um, há antes de tudo uma situação-filme 


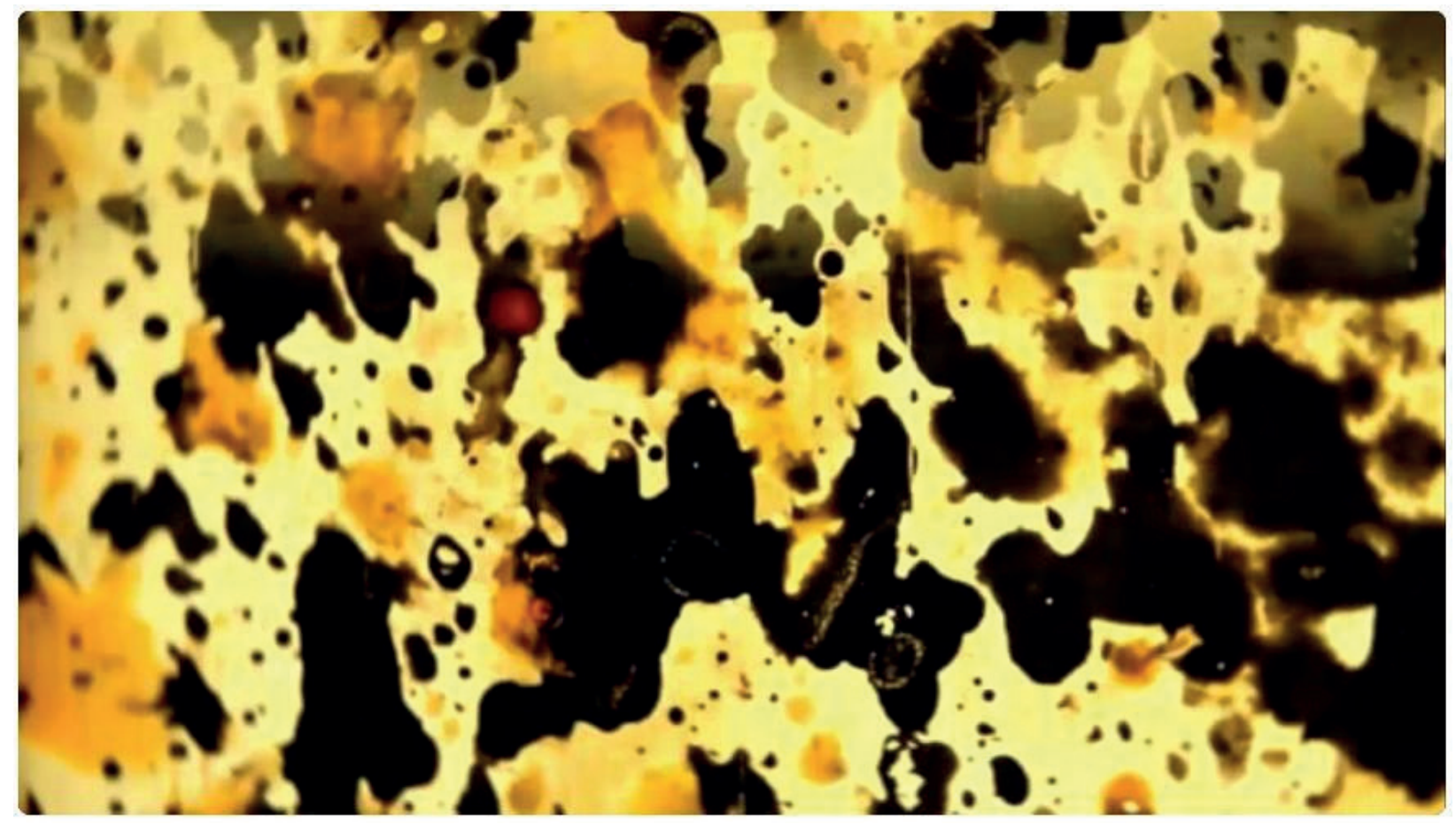

Figura 1 - Sebastian Wiedemann, Abismo, filme, 2012. Acervo do autor. Acesso em: https://vimeo.com/54427965

que não nos diz o que pensar, que não se diz palavra de ordem - não julga, faz existir - pois o que está em jogo como decisão é "dar à situação o poder de nos fazer pensar" (STENGERS, 2005). Na ecologia de práticas não se detém o poder, mas se distribui a potência. Nela não há filme, mas a situaçãofilme, que abre a virtualidade de infindáveis filmes e que de repente podem se precipitar, se atualizar como gotejar colorido em todas as direções sobre o celuloide. Isto é, este cinema do processo não administra nem gerencia o poder de agir e de ser afetado, mas dá o poder à situação, abraçando a turbulência e imprevisibilidade dos encontros. Devir guardião do diferencial, aliar-se com o acaso, com o cosmos, ali onde a situação "se torna uma questão de particular interesse e preocupação, em outras palavras, [ali onde ela] nos faz pensar e não reconhecer" (STENGERS, 2005). Ou como diria Deleuze, ali onde ela nos faz pensar pelo meio, onde não há lugar para definições que se ancorem ou para um horizonte ideal. "Abismo" pode começar e terminar a qualquer momento e nenhum pressuposto ou teoria nos daria o poder de retirar alguma componente, que faz parte de seu meio particular. Isto é, ao pensar pelo meio, ao fazermos corpo com uma ecologia de práticas não podemos nos dar o luxo de abandonar o particular, o singular e as relações internas em nome ou em direção a algo que seríamos capazes de reconhecer ou identificar por já termos uma imagem desse algo. Este cinema do processo não quer ter imagens, mas se mover, porque sempre fareja uma imagem que é infinitamente escorregadiça. Então, ele aprende a infinitamente escorregar, a fazer corpo com a imanência e a despreciar qualquer abstração que o arranque de seu meio. Enquanto ecologia, ele é sempre uma etho-ecologia, um complexo emaranhado de processos de mutua afetação intensiva. Ou para parafrasear a Spinoza, não sabemos o que pode uma prática, não sabemos no que ela é capas de devir. Ou ainda e pensando desde o viés de um empirismo radical, sempre se recoloca a perguntar por: do que a realidade é capas? (SAVRANSKY, 2019). Ela é imprevisível, assim como era impossível prever que a emergência de "Abismo" faria emergir nesta ecologia de práticas esta dobra de filme-papelescrita. Não podemos prever que ethos as práticas irão secretar, pois ao pensarmos em chave menor o que está em disputa é uma ética dos encontros que a cada vez se afirma de modo singular. Por isso Deleuze dirá do cinema experimental que é aquele que procura antes que achar. E eu agregarei, que sempre procura sem horizonte. 
Esta ecologia de práticas cinematográficas deve se abster de qualquer vontade de verdade. Não há verdade na ocasião do pensamento, onde uma proposição é desdobrada e ganha expressão. Só podemos nos perguntar pela eficácia do modo como ela afeta e faz mover o pensamento, pela eficácia do modo como se compõe ativa e potentemente com o meio da prática à que faz parte e contribui a dar consistência. Dali que toda ecologia de práticas seja um gesto pragmático que prefere a precariedade e intempérie, à proteção de uma razão geral e transcendente que Ihe de abrigo, mas que atrofie seu desvario e possibilidade de se aventurar, de fazer existir. E não só isso está em jogo, pois quando se tem intimidade com uma prática, nos os praticantes pertencemos a ela, nos co-criamos, nos coproducimos mutuamente e em alguma medida isso nos impõe obrigações. Ao me afirmar, por exemplo, como cineasta tenho obrigações, pois de mim também depende o movimento da ecologia e dela depende o movimento em mim, uma interligação que não podemos nos dar o luxo de abandonar pelo conforto da verdade e das abstrações que a sustentam. É fazer parte de uma decisão sem um fazedor-da-decisão, é sentir no corpo, no fazer corpo com, que na ausência de um fundamento o corpo de corpos da ecologia se sustenta, pois Ihe pertenço e sou capaz de fazer aquilo que eu não poderia fazer de outra maneira. Não faço o cinema que gostaria, mas aquele que posso, aquele que preciso, aquele que sou chamado a fazer. A ecologia me secreta, assim como secreta este texto que aqui estou gestando. Assim como por sua vez os afetos que ela em vocês ativa, fazem com que mesmo provisoriamente também Ihe pertençam. Todo um risco. E todo encontro é um risco e sem risco não há pensamento. Esse risco, fala de uma unidade potencial frágil que emerge como causa comum desse abismo que é o intervalo. Dali que se acontece, o encontro, como diz Stengers, tem que ser celebrado como um "acontecimento cósmico" (STENGERS, 2005). Sendo que a procura destes ínfimos acontecimentos, sempre involuntários e como germe de uma aventura do pensamento, é o que move a ecologia de práticas, enquanto um estar junto experimental de aprendizagens pragmáticos e dinâmicos do que funciona e como funciona. Aprendizagens que, por sua vez, fazem dessa procura uma cosmopolítica no desdobrar e afirmação de sua potência como construtivismo radical. Isto é, de fazer existir e não julgar, estando à altura de outrem.

Proponho agora um segundo intervalo com o filme Xapirimuu (2016), figura 2.

Outrem, como nos lembra Deleuze, é a expressão de um mundo possível (DELEUZE, 2015). E na aproximação que estamos traçando na singularidade desta ecologia de práticas cinematográficas diremos que outrem é uma dobra do intervalo, como potencial diferencial em dinamismo constante. Outrem como esse potencial de alteração dos mundos ou de fazer do mundo um pluriverso. Ele é uma potência de diferença, divergência e proliferação como condição relacional entre disparidades que se revezam a possibilidade de dizer que o mundo está por ser feito, ou está se fazendo a cada instante. Outrem como estrutura e condição de possibilidade de mundos, como esse outro do outro que mantem a relação em movimento e dinamismo, "como a condição do campo perceptivo, [sendo que] o mundo fora do alcance da percepção atual tem sua possibilidade de existência garantida pela presença virtual de um outrem por quem ele é percebido; o invisível para mim subsiste como real por sua visibilidade para outrem" (VIVEIROS DE CASTRO, 2002). Logo, então, sem outrem o mundo desmorona, pois ele é o princípio que constitui o campo perceptivo, mas por sua vez na sua relacionalidade pode modificá-lo, fazer com que ele entre em novas e impensadas configurações. Isto é, outrem é também a condição da variabilidade das matrizes perceptivas que embora possam ser habitadas pelo par objeto/ sujeito e suas representações, independem destes. É neste sentido que uma cosmopolítica da imagem, como a política que se exerce numa certa ecologia de práticas cinematográficas, ao incorporar componentes outras, não se interessa pelas formas expressivas dos outros, mas sim, pelas forças transformacionais e transmutativas que estas carregam. Essas potências de "acontecimentos cósmicos" que adiam não só a queda do céu ou o fim do mundo (KOPENAWA; ALBERT, 2015), mas a tristeza e miséria da fixação de uma imagem do pensamento (DELEUZE; GUATTARI, 1992). A aliança cosmopolítica e a causa comum que dali emerge não é com o outro, mas com o outrem que ele dramatiza, 


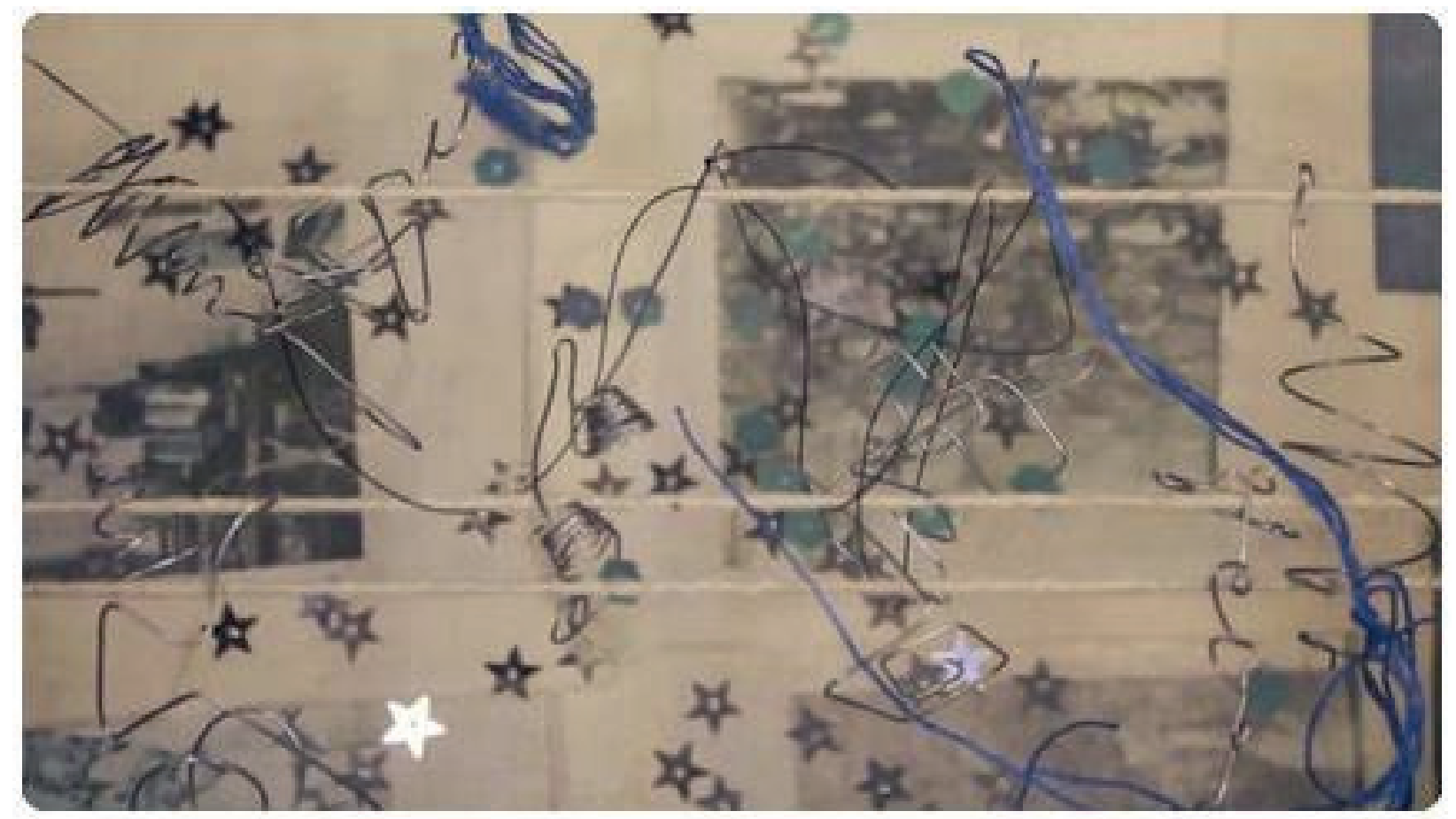

Figura 2 - Sebastian Wiedemann, Xapirimuu, filme, 2016. Acervo do autor. Acesso em: https://vimeo.com/195130177

recusando a totalização de um mundo e com ela a estagnação da potência de pensar. Se em Abismo esta dramatização aconteceu no encontro com uma vertigem cromática de molecularidades cósmicas, em Xapirimuu acontece pela aliança com as potências de pensamento Yanomami, que expandem a ecologia de práticas por meio de performatividades transformacionais cosmopolíticas de equivocidades produtivas (VIVEIROS DE CASTRO, 2018). Como temos insistido, não se trata nunca de procurar equivalências, ou muito menos de promover gestos homogeneizantes. Como diz Stengers, há a necessidade de um "princípio de precaução" (STENGERS, 2018), para não cercar o outro e pelo contrário conseguir dar vazão ao outrem que o habita e atravessa. Não só fazer existir esse mundo possível emanado por outrem, mas como gesto cosmopolítico ativar outros possíveis impensados no plano da experiência como processos de mutua transformação e inclusão (MASSUMI, 2017), sem nunca aspirar a uma síntese, a um projeto de unificação. Xapirimuu, em momento algum, tem a arrogante vontade de querer dar conta da riqueza e diversidade de pensamentos e potências audiovisuais apresentadas em $A$ queda do céu (KOPENAWA; ALBERT, 2015). Pelo contrário, na vertigem e tentando fazer corpo com uma complexa, mas instigante proposição - agir em espírito - tenta, e sempre é um risco, apreender uma certa potência transformacional, neste caso nas audiovisualidades, que passaria por ativar uma certa atmosfera afetiva que de algum modo, sempre incerto e difuso, ressoaria com os afetos Yanomami. Fiapos que não podem nem querem dizer o mesmo que Kopenawa e Albert, mas que na performance cosmopolítica que levam adiante e que integra esta ecologia de práticas, podem afirmar o gesto de "sonhar a terra entre nuvens para que o céu não caia".

O cinema por outros meios que acredito os xamãs Yanomami levam adiante e em particular Kopenawa, como modos cinematográficos de experiência outros, não só independem de um meio como o filme, mas sobre tudo independem do pressuposto da visibilidade. A matéria deste cinema é o que os Yanomami chamam de utupë e que por sua vez compõe os xapiripë. Esta matéria cinematográfica "é ao mesmo tempo não icônica e não visível" (VIVEIROS DE CASTRO, 2006), é matéria espiritual. Isto é, são espíritos que indexam "os afetos característicos daquilo de que são a imagem sem, por isso, parecerem com aquilo de que são a imagem: são índices, não ícones [...] 
seriam então como a condição daquilo de que são imagem; são imagens ativas" (Idem). E acontece que um cinema do processo só pode se interessar por "imagens ativas", por materialidades vivas, isto é, inacabadas, sempre por se fazer, que agem em espirito por estarem em metamorfismos constantes, por estarem em devir, por respirarem e comporem atmosferas heterogêneas. De algum modo, é isto o que se dá a perceber e sentir em Xapirimuu na sua diversidade de técnicas e procedimentos, sem por isto dar a ver uma imagem do pensamento de Kopenawa e do povo Yanomami. As "imagens ativas" não desvelam ou revelam, mas na imanência ativam, agenciam tendências afetivas, possibilidades impensadas de composição. Orientar-se precariamente neste agir em espirito é escutar as propensões dos blocos audiovisuais sem a priori saber em que direção o indício que eles carregam nos jogara. $\mathrm{E}$ por conta deste risco e vertigem que assim como Abismo, Xapirimuu pode acabar e começar a qualquer instante.

E já que tudo pode acabar a cada instante, então tudo tem que nascer a cada instante. A cada instante - é nossa obrigação como praticantes desta ecologia - ativar devires, fazer existir, se verter uma e outra vez no processo cosmogenético da própria ecologia, onde tudo é ativo e ativante, onde tudo contém uma potência de vida, onde tudo é força espiritual em ato e em ação com o desdobrar do pluriverso em construção e proliferação. Assim, as visualidades e sonoridades se libertam do engessamento da representação. Não há um mundo a ser representado, mas há uma necessidade de ativar forças genéticas do cosmos para que um outro e sempre nascente mundo possa ser instaurado. Em Xapirimuu, compostos audiovisuais como emaranhados de matéria-cinema análoga e digital ou que se dizem animações que emergem das mais diversas materialidades, sentem esta necessidade e chamado. Os compostos audiovisuais como todo espírito, sabem que tudo que possa ativar um devir é bem-vindo. Não é de se estranhar então que em Xapirimu, linhas, arames, rebrilhos, papeis, tecidos estejam convivendo alegremente, estejam fazendo durar a performance cosmopolítica, a situação-filme na procura desse sempre fugitivo "acontecimento cósmico" que dá consistência à ecologia de práticas e insiste em ser guardião do díspar para que a imagem não se deixe capturar. Mas a imagem paradoxalmente não para de capturar novos ritmos que a fazem sempre outra, sempre ainda por se fazer, sempre em variação.

Como foi dito anteriormente o que aqui nos interessa é um cinema que se pregunta pelo intervalo em meio à vertigem de visualidades e sonoridades, mesmo que invisíveis ou inaudíveis, mas que são atratores para o dinamismo do pensamento e das matrizes perceptivas. E certamente o pensamento de Kopenawa contamina, afirmativamente, a ecologia de práticas aqui em jogo, onde, por exemplo, um intervalar perceptivo é afirmado aqui e agora em ato, independendo de que tão visíveis ou audíveis são as visualidades e sonoridades desta atmosfera que somos de momento na passagem pela escrita e leitura.

Os Yanomami e Kopenawa como praticante de modos muito particulares de experiência cinematográfica nos ensinam que este cinema do processo deve estar aberto a um constante desestabilizar e hesitar, onde, por exemplo, estar à altura do intervalo ou do outrem que os xapiripë carregam, implica para os xamãs processos iniciáticos complexos, onde as obrigações e responsabilidades diante da ecologia de práticas são ainda mais notáveis e iminentes. A literalidade de estar sempre em meio a um grande cinematografo cósmico em formação, é tremendamente vertiginosa. E é com essa vertigem que um cinema do processo é chamado a fazer corpo. Assim, ao integrarmos estas forças de pensamento Yanomami à ecologia que aqui nos convoca, ela palpa com mais claridade que nunca estamos lidando com fatos ou com uma natureza das coisas. Pelo contrário, lidamos e nos doamos à emergência de proposições, ocasiões e situações disparadoras de ativação, de ação e transformação que fazem da cosmopolítica uma política dos afetos, sempre mais do que humanos, que se recusam a servir a um senhor, à Natureza (não existe tal domo unificador), a qualquer transcendência. Uma política que em todo caso só serviria a uma contra-transcendência que Stengers chama de "intrusão de Gaia" (SZTUTMAN, 2018) e que nós chamaremos de ponto de vista da criação, onde como insistimos 
ontologias e mundos são feitos, são compostos. Um composicionismo contra-natura que só se ergue, por que cria condições de existência para o diverso, para o estar junto do diferente e onde todos somos atmosfera, onde todos somos meio e estamos no meio.

Sendo atmosfera como "um agregado de mundos divergentes que não aceitam um representante comum" (SZTUTMAN, 2019), vertemo-nos inexoravelmente num plano da experiência povoado de multiplicidades de emergência livre, onde sem transcendência ganhamos um maior grau de intimidade com o caos e seus modos de aparecer sempre fortuitos, mas ricos em cosmicidade. Assim o precursor sombrio de outrem sempre é o caos, mas outrem como passagem de cosmicidade e intervalo, é a nascente, da qual mundos são engendrados. Neste intervalar ao sermos participantes e praticantes desta ecologia temos a obrigação de cuidar essa ocasião-berçário onde essas faíscas de vida estão em constante eclosão. Isto é, onde elas se afirmam como a multiplicação de contraimagens ativas que fazem do cinema não só um gesto cosmopolítico, mas também uma vertigem xamaneante de transformação entre mundos, de ponte com o fora.

No encontro, na criação de vínculos parciais com as potências de pensamento Yanomami, os modos de acontecer do plano da experiência cinematográfica ganham novas nuanças experimentais, explicitando que assim como a magia e bruxaria o que tem que ser cultivado "é uma arte da atenção imanente, uma arte empírica que investiga o que é bom ou nocivo" (STENGERS, 2017) para a ecologia de práticas e o processo cosmogenético que esta leva adiante. É nesse sentido que os xamãs são radicalmente pragmáticos e "experimentam efeitos e consequências do que, como el[e] s sabem, nunca é inócuo, e envolve cuidado, proteção e experiência" (Idem) e que de algum jeito "Xapirimuu" explora ao evocar vestígios da mitologia metálica que Kopenawa apresenta.

Como etho-ecologia, este cinema do processo sempre tem que ser um gesto de cuidado e cura, e por tanto de resistência. De resistência a qualquer vontade de tornar a matéria impotente ou inativa. Isto é, estéril e impossibilitada de entrar em relações e conexões outras às já conhecidas e esperadas. Sabendo que tudo pode devir matériacinema, mas também tudo pode adoecer; cuidar e se for necessário curar, justamente para que ela, a matéria-cinema, possa se tornar material. Isto é, possa entrar em processo de composição, de co-criação e co-evolução. Em outras palavras, assim como o corpo do xamã e a prática de fazer corpo do xamã, ser poroso, permeável, maleável, aberto a fractalidades e passagens de baixa aderência. Esse foi talvez, e sempre como um risco e vertigem, o que orientou a situaçãofilme de "Xapirimmu" entre indiscernibilidades, mas também modulações singularizantes de uma dramatização contingente, onde se tenta fazer escuta da língua secreta das visualidades e sonoridades, sem que essa escuta desvele o secreto. Do contrário, deixaríamos de ser guardiões do diferencial e do epicentro ilocalizável e inominável das virtualidades que sustentam e são a causa desta cosmopolítica da imagem. Escutar o murmulho do cosmos no abismo que é o intervalo, mas nunca se perguntar de onde vem ou para onde vai. Tão só multiplicar as superfícies por onde pode proliferar e se modular. Esse simples e ao mesmo tempo complexo gesto, como continuidade na descontinuidade, atravessa permanentemente a performance cosmopolítica.

Os Yanomami nos doam um conceito riquíssimo com a polissemia construtivista que a noção de utupë carrega e que cria um ponto de não retorno nesta ecologia de práticas, ao fazêla entrar em transformações não só por fazer com que ela incorpore novas componentes, mas porque estas componentes assim como as outras que já compõem o complexo rizomático, já não conseguem parar de remexer e chocalhar os processos morfogenéticos. Imagens ativas que se desdobram fractalmente em devires e metamorfismos constantes e que tem o poder de especular (VALENTIM, 2019). Contra-imagens que carregam uma fertilidade, uma força engravidante que as faz multiplicidade e fluxo de heterogeneidades. Elas estão vivas, são espíritos, agem em espirito, pois sua agencia move um mundo tão intensamente que este não para de se abrir em novos modos de existência. Elas são atratoras de transformação, pura propensão aos devires. Utupë nos faz lembrar que somos parte da mesma linhagem, do mesmo processo cosmogenético e que, portanto, fazemos parte do 


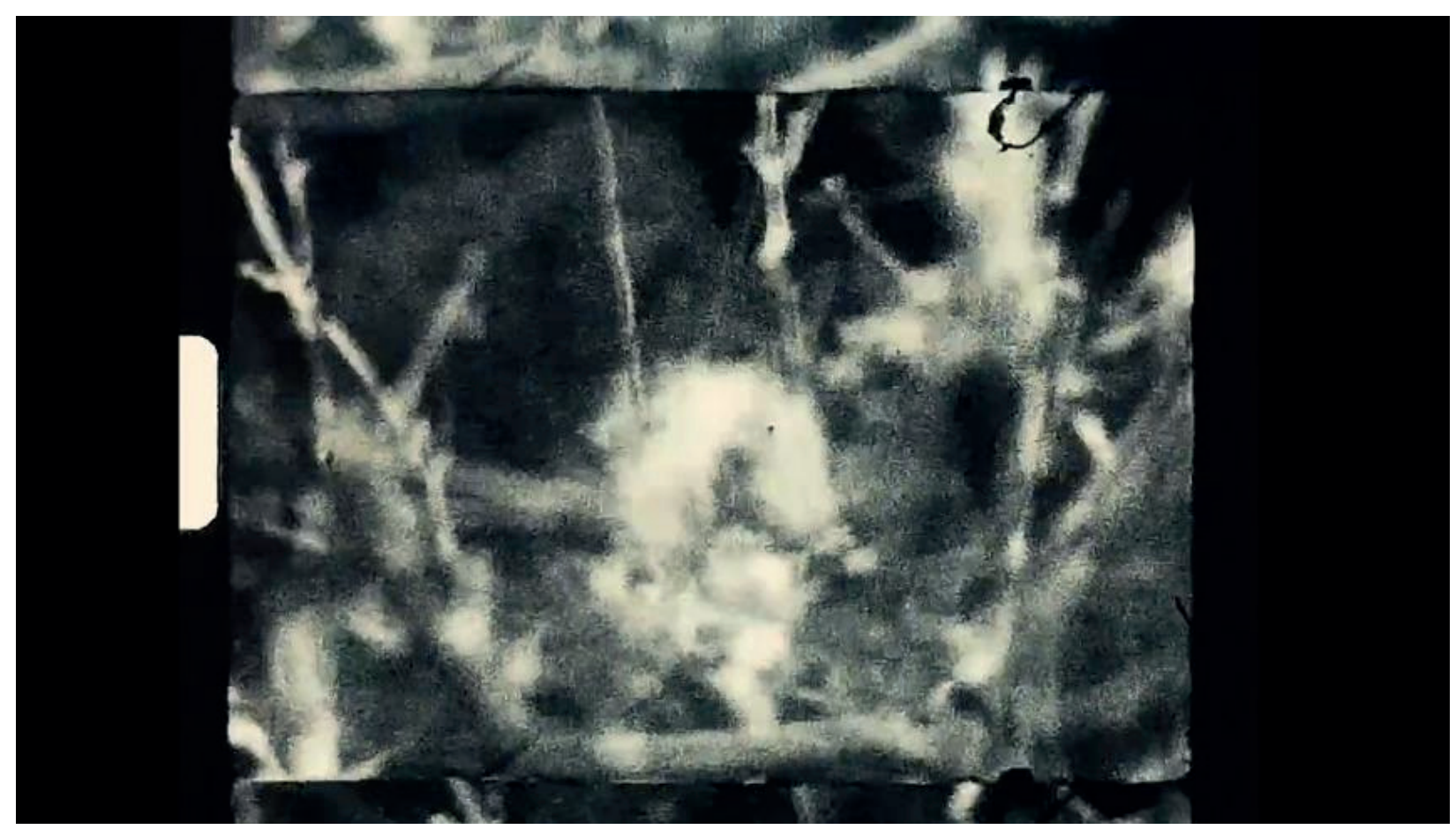

Figura 3 - Sebastian Wiedemann, Obatala, filme, 2019. Acervo do autor. Acesso em: https://vimeo.com/338893751 (password: obatala)

constante entrecruzamento de perspectivas que multifacetam o mundo, multiplicando as entradas e fluxos de outrem e com ele de novos modos de existência. Series infindáveis de ocasiões embrionárias, onde, por exemplo, esta ocasiãofilme-papel em ato e que vocês estão lendo agora, devem utupa sipë ou "pele de imagens" como os Yanomami chamam as inscrições sobre papel.

Com utupë insistir em que um cinema do processo sempre tem que estar disposto a acontecer por outros meios, a se multiplicar por inúmeras e impensadas superfícies, a ser espirito e espiritual por possuir corpos demais que desbordam qualquer forma, até quase explodir e fazer colapsar o plano do audível e visível. Um cinema que pode atingir umbrais espectrais, pois como conglomerado espiritual "só é escasso de corpo na medida em que possui corpos demais" (VIVEIROS DE CASTRO, 2006) que são instáveis e ao mesmo tempo disjuntivos. Um cinema que em sua espectralidade pensa o mundo. Isto é, que no seu potencial metamórfico constitutivo como agente cósmico "encarna uma estrutura de pensamento intensamente transformacional, assubjetiva" (VALENTIM, 2019), onde como nos lembra Deleuze pensar é sempre criar e diferenciar.
A noção de utupë se apresenta como conceito, pois ela se afirma como um hiper-conglomerado de relações que dinamicamente condensam uma qualidade de vórtice e vector para o pensamento. Utupë não só afeta o modo como os blocos audiovisuais se compõem em "Xapirimuu", mas já que as audiovisualidades desta ecologia de práticas sempre tem um avesso conceitual, por sua vez nutrem a possibilidade de dar maior consistência às noções de kino-madologia e etologia poética que povoam este plano da experiência como zonas críticas de transversalidades entre heterogêneos. Com utupë podemos afirmar que esta kinomadologia e etologia poética são habitadas por seres pensantes, por contra-imagens ativas, que como ocasiões para o pensamento, que como ocasiões-filme, papel, conceito, como temos explorado aqui, detêm perspectivas por onde outrem vaza. E não esqueçamos que o proliferar de outrem depende do proliferar e dinamismo das perspectivas, como fugas intervalares espectrais que sustentam o mundo e a imagem. Sendo que a imagem não é o que se dá a ver no mundo ou do mundo, mas o que o sustenta, incluindo nossos próprios corpos, por ser esse fora que como núcleo dinâmico e agencia espectral é vibração difrativa e não reflexiva que não deixa estagnar o movimento. 
Em outras palavras, a preocupação e obrigação desta cosmopolítica é cuidar da eficácia da imagem e que como veremos no seguinte intervalo, com os Yoruba e com Ifa, pode ganhar tonalidades impensadas que continuam a afirmar que a vertigem é um fator primordial para, na imanência e pelo meio, habitar o cinematografo cósmico que é o mundo.

A possibilidade de se abismar nesta experiência cinematográfica e ocasião-filme, que antes de tudo é uma experiência vital de encontro entre mundos, não teria sido possível sem a imensa generosidade de Oba Ojele e Obalesun do Templo de Obatala da cidade sagrada de Ile-Ife, lar primordial dos Orisas na Nigéria. Também sou profundamente grato a Ifakola, diretor da Obatala Arts \& Culture Academy e antigo aluno do Ifa Heritage Institute, quem fez possível que conhecesse o Wándé Abímbọ́lá, Àwíse Awo Àgbàyé.

"Obatala Film" se apresenta como uma ocasiãooferenda-filme, que complica e torna mais ricas as possibilidades dos modos de experiência cinematográficos, pois a noção de oferenda só pode ser afirmada na medida em que toda uma ecologia de práticas Yoruba também é afirmada e incorporada. Este cinema por outros meios se move e compõe na pergunta pelo intervalo entre Orun e Aiye, entre o mundo espiritual e o mundo físico, entre um plano de virtualidades de mundos por vir e sua atualização, que afirma uma política onde o cosmos insiste fazendo proliferar as divergências, a diferença. A filosofa Yoruba e Ìyánífá Sophie Oluwole, dirá que “Ifa não é religião, mas contem religião; que não é história, mas contem história; que não é filosofia, mas contem filosofia; que não é ciência, mas contem ciência" (OLUWOLE, 2014). Em outras palavras, que é uma multiplicidade de potências genéticas de mundos que se nega a ser uma totalidade, ou para melhor dizer, que se preocupa por cuidar do secreto e mistério do mundo. E não esqueçamos que o termo babalawo, quer dizer pai/guardião dos mistérios e por tanto da sabedoria, do cognoscível. O babalawo é o guardião daquilo que pode vir a ser atualizado como possível no mundo e que por tanto mantem o mundo em processo, em recriação constante, em movimento.

Ao fazermos corpo com a potência de pensamento de Ifa, podemos reformular a proposição de Sophie
Oluwole, ao dizermos que este cinema do processo não é religião, nem filosofia, nem antropologia, mas de algum modo os inclui, pois como Ifa antes de tudo se preocupa pelo metamorfismo do pensamento e sua eficácia diante de um problema concreto. Todo um gesto onde esta ecologia de práticas que estamos levando adiante ganha valor por "sua efetividade em introduzir novos seres (novas agências), ou, mais precisamente, de estabelecer novas relações no mundo" (DE CASTRO COSTA, 2017) e onde como não paramos de insistir "os termos da relação não a precedem: eles emergem simultaneamente, num processo de captura recíproca [de mútua inclusão] que faz surgir" (Idem). Nesta coprodução que mantem ativo o processo cosmogenético participam não só forças humanas, mas, sobretudo, mais do que humanas. Condição que os babalawo entendem muito bem. Eles sabem que no processo sempre estão participando ativamente outros-quehumanos, e que não há criação, mas sim co-criação imanente onde não pode existir hierarquia entre os termos. Fazer existir e não julgar. Saber que um cinema do processo sempre é multirelacional e tem a obrigação de agregar a diferença sem torna-la impotente. Ou seja, um cinema que com a diferença abre novas potências. Um cinema que afirma uma cosmopolítica da imagem, por insistir em ser um exercício especulativo que pretende suspender os hábitos de hierarquizar e julgar, para que a experiência (cinematográfica) possa ser efetivamente um processo de experimentação que sempre corre riscos, que tateia, que abraça as incertezas e a catástrofe, que não tenta fugir do caos. Um processo de experimentação como experiência do pensamento, onde como diz Deleuze e Guattari "pensar é sempre seguir a linha de fuga do voo da bruxa" (DELEUZE; GUATTARI, 1992) ou neste caso dos babalawo e onde a cocriação acontece, pois insistimos em ser capazes de pensar na presença de outros, mas, sobretudo, sob a influência do outrem que eles carregam. Gesto que implica não querer possuir um poder, aquele humano humano demais e que não se diz intensivo, mas se tornar praticante e passagem que não desqualifica, mas vaza e escorrega entre meios como potência e força criadora nômade e fugitiva. Com os babalawo os modos de experiência cinematográficos não só têm que devir guardiões do díspar e do diferencial, mas também do mistério e segredo. 
Esta ecologia de práticas cinematográficas, só se sustenta na medida em que é recusa de qualquer base universalizante, antropocêntrica ou etnocêntrica. Em outras palavras, se sustenta justamente por não ter fundamento, por acontecer pelo meio, onde ativamente recusa "qualquer recurso ou critério que transcenda determinada questão e o meio concreto em que ela [a pratica] emerge" (DE CASTRO COSTA, 2017). Nesse sentido "Obatala Film" é um gesto cosmopolítico e de descolonização do próprio cinema, pois assume coexistências, assume que nunca estamos sozinhos no mundo, mas, sobretudo, porque assume a necessidade de devir-com, de fazer do cinema um gesto animista como "agenciamentos que geram transformações metamórficas em nossa capacidade de afetar e sermos afetados - e também de sentir, pensar e imaginar" (STENGERS, 2017).

Em "Obatala Film" entramos pelo meio e o que se dá a ver de entrada é a vertigem do indeterminado, como processualidade de uma inteligência coletiva e impessoal composta entre filme e Ifa como cinema por outros meios e onde praticantes e práticas se reúnem por uma causa comum (SZTUTMAN, 2018), onde o gesto expressivo não pode se dizer privativo, mas sim tendência co-evolutiva e compartilhada do próprio processo. Devir praticante de modos de experiência cinematográficos com Ifa é estar à altura do destino que nosso Ori carrega e que inevitavelmente implica uma ética radical dos encontros. Ética que como causa comum cuida e cura das condições de possibilidade que fazem com que a imagem seja sempre aquilo que está por vir, seja esse secreto e mistério que se recusa a ser totalmente cognoscível e pensável, mas que move o pensamento. o babalawo, não é só pai e guardião do secreto, mas também da imagem.

"Obatala Film" como ocasião do pensamento sabe da potência do fragmento, a mesma que faz com que o corpo literário de Ifa, não se manifeste como uma totalidade continua e fecha, mas sim como fragmentos e fractalidades por meio da divinação. O corpo literário de Ifa é uma espécie de reserva de cosmicidade em constante expansão e renovação que depende do dinamismo gerado entre o babalawo e o consultante. Nesse sentido, perguntar a Ifa e fazer com que o processo de divinação aconteça, não é perguntar pelo futuro como se fosse algo já dado, mas perguntar pelos modos como as potências de futuro podem se atualizar no mundo, fazendo dele outro. Ifa é vetor de organização e composição do caos, é um atrator morfogenetico onde babalawo e consultante são meios e canais que tem a obrigação de fazer circular e proliferar afirmativamente o ase, a força vital que compõe e renova o mundo. Tal circulação e proliferação se singularizam e ganham tonalidades particulares na aliança com os mais diversos Orisas. E se aliar com um Orisa não é outra coisa do que intensificar a eficácia de uma ética. Ética que depende do Ori, que é a nossa cabeça tanto física como espiritual e que contém um destino, que poderíamos entender como a obrigação de cultivar a maior potência de agir e onde a oferenda é um catalizador para este propósito. Em outras palavras, o Ori se alia com aquele que tem uma cabeça mais intensa e potente, com um Orisa (aquele que tem um Ori maior, mais forte) sendo que o diferencial ali presente é só de grau e não de natureza. Do contraio não seria possível receber um Orisa no próprio corpo, quando do que se trata é de fazer corpo com, é de devir-com. Ou seja, de fazer da aliança caminho de convergência diferenciadora entre Orun e Aiye. É nesse sentido que a devoção e as oferendas são o modo de manter vivo e intensificar a aliança, o vínculo, o canal com o Orisa para que o ase possa circular. Circulação onde sempre estarão implicados Ifa e Esu. Ifa como vetor de composição e organização, e Esu como potencial de conectividade, como liga cósmica. Não esqueçamos que Esu não só sabe todas as línguas do cosmos, mas é um mensageiro entre Orun e Aiye, entre o céu espiritual e a terra material. E embora não dependa só dele, ele está no cerne do circuito virtual-atual ao ser a liga entre estes.

O babalawo como articulador de possíveis, ou para melhor dizer, de condições de instauração dos possíveis entra em relação com os Odus, que são os fragmentos-componentes do corpo divinatório de Ifa e que por sua vez contem inúmeros versos. Certamente só um babalawo não pode acessar a todos, dali que muitas vezes as sessões aconteçam com vários babalawos. 0 que reafirma o caráter impessoal e relacional da ecologia de práticas Yoruba, onde o babalawo, não detém o poder, mas sim é aquele que por ter intimidade com Ifa pode sugerir caminhos para a propensão das potências de cosmicidade 
que Ifa carrega. É assim como "Obatala Film" ao ser uma ocasião-oferenda aspira afirmar a força espiritual dos Orisas com que temos estabelecido uma aliança. Com Obatala, Orisa da criação e da criatividade, mas também com Osun, Orisa das águas, dos fluxos e mãe primordial.

Na ocasião-filme se conjugam concomitantemente as forças de Ifa, Esu, Obatala e Osun. Ifa e Esu via a instauração de uma composição audiovisual que diz dos gestos do babalawo, dos gestos de quem é guardião do segredo, de quem cuida do segredoimagem ao fazer com que esta não se fixe. Dali o apelo ao transe, à vertigem na composição. Ao mesmo tempo, sendo que o destino é sempre fazer seguir o ase que faz proliferar a vida, as sonoridades se apresentam como fazer escuta do ritmo do cosmos, do seu fluxo, onde Osun ressoa fortemente. Fluxo que sempre é criação, que sempre é afirmação de Obatala. Como dobra deste gesto, vemos por sua vez, o nascimento de Oba Ojele, sua coroação como um dos reis do Templo de Obatala que não é mais do que o desdobrar e devir de forças cósmicas, de forças moleculares das águas, das folhas, dos rebrilhos que se corporificam e onde mais uma vez Osun e Obatala se manifestam, se afirmam como caminho e caminhada. Ocasiãooferenda-filme, como ocasião onde as forças dos Orisas entram em ação.

Neste ponto já podemos sentir o que implica fazer funcionar uma ecologia de práticas cinematográficas e que tão rica ela pode se tornar. Não só a ecologia, mas o cinematografo cósmico em expansão, fazendo comunidade e promovendo causas comuns, carregando forças moleculares, forças dos Yanomami e dos Yoruba, sabendo que nunca se chega, que a tarefa sempre está por ser feita e com ela a constante renovação de fazer cinema por outros meios, onde como os babalawos nos ensinam sempre se começa por segunda vez e não por primeira. Acolher o fato sempre vertiginoso de que fazemos parte de um corpo sem órgãos, como o é o corpo literário e divinatório de Ifa. Assim mesmo abraçar o presente que é carregar um Ori que exige constantemente uma plasticidade neuro-espiritual de uma ética dos encontros cósmicos, onde sempre retorna a pergunta por se estamos à altura de fazer corpo com o ponto de vista da criação.
Do que é capas a realidade, enquanto cinema do processo, enquanto cinematografo cósmico? Não sabemos. Só nos cabe abraçar o mistério e insistir em que a ecologia de práticas através de suas performances cosmopolíticas cultive o pluriverso, onde reaprendemos a confiar no mundo uma e outra vez e onde "sem garantia alguma, apostamos contra toda probabilidade por um talvez" (SAVRANSKY, 2019) que se diz intervalo e que sussurra: "Sempre ainda não! Sempre ainda não!" como "a impossibilidade de incluir tudo e a necessidade de não desqualificar nada." Um sussurro, um "gesto menor" (MANNING, 2016) que é muito menos "uma proibição e mais um programa de trabalho e experimentação" (SAVRANSKY, 2019).

\section{CODA}

Para provisoriamente terminar estas notas que sempre devem ser inconclusas direi que esta ecologia de práticas sempre exige redobrar a aposta. A aventura do pensamento só avança na tensão constante de seus supostos limites, para que eles sempre sejam dinâmicos. As obrigações, diante do chamado da contratranscendência, que é o ponto de vista da criação pede um constante refinamento do fazer escuta, onde cada vez mais estejamos à altura da propensão do que nossos corpos podem no emaranhamento de situações potenciais onde as dramatizações do pensamento devem ser cada vez mais radicais, onde a vertigem seja cada vez maior. Tanto os Yanomami, como os Yoruba, tem sido intercessores imprescindíveis para esta aprendizagem mais do que humana de agir em espirito sentindo $O$ ase presente nos encontros. $E$ sem dúvida o meu encontro com Obatala, Osun, Esu e Ifa, tem sido um "acontecimento cósmico", onde tem se aguçado a minha afinidade afetiva pelos planos de experiência de tendência aquosa nos quais aqui não tive tempo de me deter, mas onde, por exemplo, já emergiram situações-filme como "Ondas" (2015)².

A minha ligação com as águas é algo que não posso refutar, pois elas são a atmosfera, a qual, antes de qualquer outra, pertenço. Uma certa kino-madologia que atravessa este cinema do processo e esta ecologia de práticas, faz com que os encontros sempre sejam passagens de passagens. E o encontro com estas alteridades 


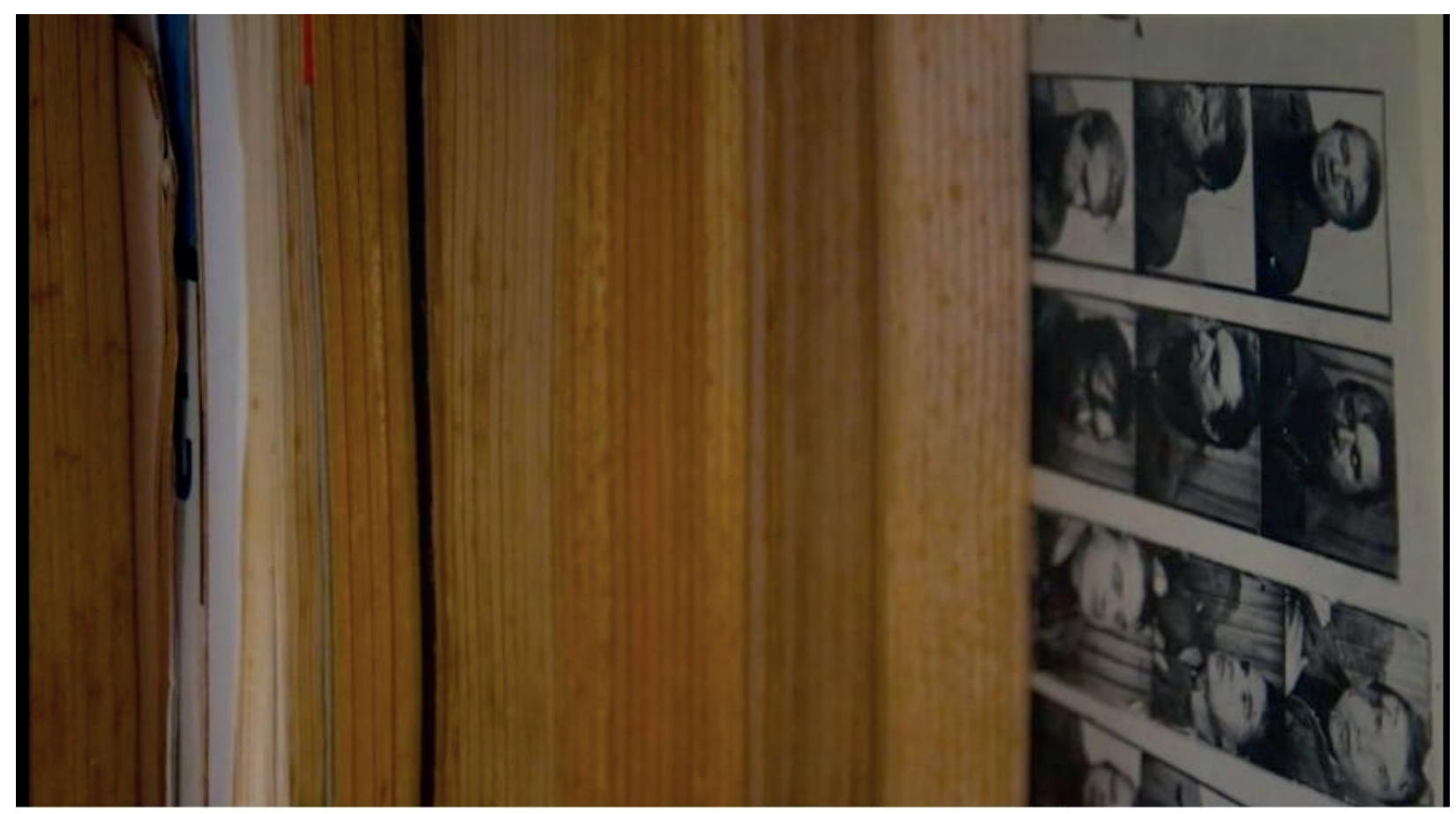

Figura 4 - Orssarara Collective, Cintilações, 2018. Disponível em: https://vimeo.com/292308770

radicais e extra-modernas, tem sido a passagem necessária para intensificar a pergunta por como continuar afirmando modos cinematográficos de experiência que destilem gestos de emergência criadora que tornem mais potente a conectividade e fluência do pensamento, assim como a proliferação e expansão do pluriverso. Tornar rico e complicar o problema que move esta pergunta, que aqui nos move, inevitavelmente me jogou na iminência da instauração de um novo cenário e fabulação especulativa (HARAWAY, 2013), o "Azul profundo", e que agora também integra a performance cosmopolítica que aqui insiste.

Estar à altura de outrem impõe esse desapego do outro e de suas formas, para justamente fazer com que os afetos que dele emergem e agora nos compõem, nos arrastem em direções e dimensões impensadas. Passar, saber que sempre se deve continuar por outros meios. E simplesmente enuncio a atual existência do "Azul profundo", 3 para destacar a responsabilidade que impõe uma cosmopolítica da imagem que só pode se dizer eficaz, se está em constante movimento e instabilidade. Hoje a ecologia de práticas além de tudo o que já aqui se deixou sentir, perceber e apreender agrega também o "Azul profundo" e com ele, práticas de animalidades marinhas, de polvos (GODFREY-SMITH, 2019) lulas e águas-vivas ou de humanidades neurodiversas entre o autismo (MANNING, 2016) e o Alzheimer de cérebros azuis (MALABOU, 2019), assim como gestos que excedem uma antropologia que por se dizer mais do que humana, se diz xenologia (VALENTIM, 2018). Fazer existir, não julgar. De repente o cinematografo cósmico está submerso no "Azul profundo". Não sabemos quanto pode durar e no que mais, e que não podemos prever, irá desabrochar. Só nos cabe insistir em estar no meio e pelo meio fazendo cintilar infindavelmente as forças do cosmos e do pensamento, como nos lembra meu querido amigo Luiz Orlandi neste último intervalo audiovisual que a vocês apresento.

Cabe-nos então fazer corpo com as práticas e técnicas de que dispomos, mas também inventálas, renová-las para que as ecologias sempre sejam alargadas e outras. Um cinema do processo se serve de qualquer meio e sempre está disposto a acontecer por outros meios, qualquer que sejam: escrita, filme, fala, divinação e qualquer outro que possa ser imaginado, mas que prove sua eficácia ao tornar mais potente a performance cosmopolítica que faz do mundo uma nascença incessante e da imagem algo sempre por vir. 


\section{NOTAS}

1. Umaprimeiraversão deste texto foiapresentada a modo de palestra de abertura no evento “Estágio Intensivo Master Europhilosophie/ UNILAB: Seminário Filosofias no Sul Global e $2^{\circ}$ Encontro de Geofilosofia" (2019). Agradeço especialmente a Cleber Daniel Lambert da Silva pelo generoso convite.

2. Filme disponível em: < https://vimeo. com/167269853>

3. Para ganhar maior intimidade com o "Deep Blue: Future Memories of a Living's Cinematic In-Between". Livro-objeto e filme especulativo disponível em: < https://evidenceannual.co/Sebastian-WiedemannAzul-Profundo-Deep-Blue >

\section{REFERÊNCIAS}

DE CASTRO COSTA, Alyne. Ecologia e resistência no rastro do voo da bruxa: a cosmopolítica como exercício de filosofia especulativa. ANALóGos, [S. I.], v. 17, n. 1, 2017. Disponível em: https:// doi.org/10.17771/PUCRio.ANA.31514. Acesso em: 8 ago. 2019.

DELEUZE, Gilles. Crítica e clínica. São Paulo: Editora 34, 1997. E-book.

DELEUZE, Gilles. Lógica do Sentido. Edição: $5 a$ ed. São Paulo (SP): Perspectiva, 2015. E-book.

DELEUZE, Gilles; GUATTARI, Félix. o que é a filosofia? Rio de Janeiro: Editora 34, 1992. E-book.

GODFREY-SMITH, Peter. Outras Mentes: O Polvo e a origem da consciência. Edição: 1a ed. [S. I.]: Todavia, 2019. E-book.

HARAWAY, Donna.SF: Science Fiction, Speculative Fabulation, String Figures, So Far. [S. I.], 2013. Disponível em: https://doi.org/10.7264/ n3kh0k81. Acesso em: ago. 2019.

JAMES, William. Essays in Radical Empiricism.

Mineola: Dover Publications, 2003. E-book.

KOPENAWA, Davi; ALBERT, Bruce. A Queda do Céu. São Paulo: Companhia das Letras, 2015. E-book.

MALABOU, Catherine. Morphing Intelligence: From IQ Measurement to Artificial Brains. Tradução
Carolyn Shread. Translation edition ed. New York: Columbia University Press, 2019. E-book.

MANNING, Erin. The Minor Gesture. Durham: Duke University Press Books, 2016. E-book.

MASSUMI, Brian. 0 que os animais nos ensinam sobre política. São Paulo: $n-1$ edições, 2017. E-book.

OLUWOLE, Sophie B. Socrates and Òrúnmilà: Two Patron Saints of Classical Philosophy. [S. I.]: Ark Publishers, 2014. E-book.

ORLANDI, Luiz B. L. Revendo nuvens. ClimaCom, [S. I.], v. 7, p. 91-117, 2016.

SAVRANSKY, Martin. Pensar el Pluriverso: Elementos para una filosofía empírica. Diferencias, [S. I.], v. 1, n. 8, 2019. Disponível em: http://www. revista.diferencias.com.ar/index.php/diferencias/ article/view/180. Acesso em: ago. 2019.

STENGERS, Isabelle. Introductory Notes on an Ecology of Practices. Cultural Studies Review, [S. I.], v. 11, n. 1, p. 183-196, 2005. Disponível em: https://doi.org/10.5130/csr.v11i1.3459.

STENGERS, Isabelle. Reativar o animismo. Cadernos de Leitura, [S. I.], v. 62, p. 2-15, 2017.

STENGERS, Isabelle. A proposição cosmopolítica. Revista do Instituto de Estudos Brasileiros, [S. I.], n. 69 , p. 442-464, 2018. Disponível em: https://doi. org/10.11606/issn.2316-901X.v0i69p442-464.

STRATHERN, Marilyn. Partial Connections. Edição: Updated Edition ed. Walnut Creek Lanham New York Toronto Oxford: Altamira Press, 2005. E-book.

SZTUTMAN, Renato. Reativar a feitiçaria e outras receitas de resistência - pensando com Isabelle Stengers. Revista do Instituto de Estudos Brasileiros, [S. I.], n. 69, p. 338-360, 2018. Disponível em: https://doi.org/10.11606/ issn.2316-901x.v0i69p338-360.

SZTUTMAN, Renato. Um acontecimento cosmopolítico A proposta de Stengers e o manifesto de Kopenawa. Mundo Amazónico, [S. I.], v. 10, n. 1, 2019. Disponível em: https://doi.org/10.15446/ ma.v10n1.74098. Acesso em: ago. 2019.

VALENTIM, Marco Antonio. Antropologia \& Xenologia. Revista ECO-Pós, [S. I.], v. 21, n. 2, p. 343, 2018. Disponível em: https://doi. org/10.29146/eco-pos.v21i2.20499. 
VALENTIM, Marco Antonio. Utupë: A imaginação conceitual de Davi Kopenawa. [S. I.], v. XII, n. 24, p. 193-216, 2019.

VIVEIROS DE CASTRO, Eduardo. O nativo relativo. Mana, [S. I.], v. 8, n. 1, p. 113-148, 2002. Disponível em: https://doi.org/10.1590/S010493132002000100005.

VIVEIROS DE CASTRO, Eduardo. A floresta de cristal: notas sobre a ontologia dos espíritos amazônicos. Cadernos de Campo, [S. I.], v. 15, n. 14-15, 2006, p. 319-338.

VIVEIROS DE CASTRO, Eduardo. Metafísicas canibais: Elementos para uma antropolia pósestrutural. São Paulo: Ubu Editora, 2018. E-book.

WHITEHEAD, Alfred North. Process and Reality. New York: Free Press, 1978. E-book.

WHITEHEAD, Alfred North. The Concept of

Nature. New York: Cosimo Classics, 2007. E-book.

\section{SOBRE O AUTOR}

Sebastian Wiedemann: Cineasta-pesquisador, doutorando em Educação na área de Praticas Artísticase Aprendizagem(FE/Unicamp), investiga na intersecção entre cinema experimental e filosofia a possibilidade de aprendizagens mais do que humanas entre escrita, curadoria e realização. Possui mestrado em Estudos Contemporâneos das Artes - UFF (2016), especialização em Estudos Cinematográficos - Universidad del Cine (2013, Argentina), graduação em Direção Cinematográfica - Universidad del Cine (2010, Argentina) e graduação em Artes Visuais pelo Instituto de Bellas Artes (2005, Colômbia). No campo problemático que se cria entre cinema experimental e filosofia, atua principalmente nos seguintes temas: pesquisa-criação [researchcreation], pedagogias radicais dos processos de criação, composição audiovisual, modos de experiência cinematográficos e cinema e pensamento (Gilles Deleuze). Sua obra cinematográfica já recebeu retrospectivas na Espanha, Irlanda, Colômbia e no Brasil. Editou os livros "La Radicalidad de la Imagen. Desbordando latitudes latinoamericanas. Sobre algunos modos del cine experimental." (2016), "Conexões: Deleuze e Cosmopolíticas e Ecologias
Radicais e Nova Terra e..." (2019) e "Pensamientos Migrantes: Intersecciones cinematográficas." (no prelo, 2020). Mais recentemente publicou como autor o livro “Deep Blue: Future Memories of A Livings Cinematic In-Between" (2019). Financiamento: CNPq - Conselho Nacional de Desenvolvimento Científico e Tecnológico.

E-mail: wiedemann.sebastian@gmail.com 